\title{
¿Los gobiernos locales y el desarrollo local una agenda emergente ante la crisis cubana o una transformación del modelo?
}

\section{Are local governments and local development an emerging agenda in the face of the Cuban crisis or a transformation of the model?}

\author{
Addiel Pérez Díaz ${ }^{a}$
}

\section{Resumen}

El artículo esboza los antecedentes del desarrollo local que se fueron materializando en la búsqueda de un modelo económico, social y político que comienza a gestarse con el triunfo de la Revolución Cubana. Se presentan las particularidades de los gobiernos locales en nuestro contexto y cómo a diferencia de la ocurrencia de procesos reales de descentralización a nivel regional, nuestro país fue orientándose cada vez más hacia un modelo excesivamente centralizado. Al mismo tiempo se contextualiza el surgimiento del tema del desarrollo local en los noventa y las iniciativas generadas a raíz de los cambios ocurridos en el período señalado. Se ofrecen también las contradicciones y rasgos más esenciales que marcan el debate por el desarrollo y los gobiernos locales en el contexto actual. Se valoran las posibilidades que existen, desde los territorios y en especial en los gobiernos locales para propiciar procesos de desarrollo local.

Palabras clave: Cuba, gobierno local, crisis de la sociedad cubana, descentralización.

\begin{abstract}
The article outlines the record of local development that were materialized in the search for an economic, social and political model that's born along the triumph of the Cuban Revolution. The particularities of local governments in our context are presented and how, unlike the occurrence of real processes of decentralization at the regional level, our country was increasingly oriented towards an excessively centralized model. At the same time, the emergence of the topic of local development in the 1990s and the initiatives generated as a result of the changes that occurred in the period in question are contextualized. The most essential contradictions and features that mark the debate for development and local governments in the current context are also offered. The possibilities that exist, from the
\end{abstract}

a Universidad Autónoma de Ciudad Juárez, México.

Correspondencia a: addiel.perez@uacj.mx

Recibido:

7 octubre 2019

Aceptado:

3 diciembre 2019

Artículo publicado en acceso abierto bajo la Licencia Creative Commons.

\section{(c) (i)}

Cita:

Pérez Díaz, A. (2019). ¿Los gobiernos locales y el desarrollo local una agenda emergente ante la crisis cubana o una transformación del modelo? Kera Yvoty: reflexiones sobre la cuestión social, 4, 77-91. 
territories and especially in the local governments, to promote local development processes are valued.

Keywords: Cuba, local government, crisis of Cuban society, decentralization.

\section{Introducción}

La descentralización hacia actores no tradicionales como generadores del desarrollo empieza a extenderse por gran parte del mundo a partir de la década del setenta y ochenta al calor de la crisis de los Estados de Bienestar. Así, frecuentemente, desde organismos internacionales se estimula a las políticas descentralizadoras como la solución a los problemas que enfrentan los gobiernos, y se responsabiliza a la gobernabilidad centralizada como la causa fundamental de esos males: ineficiencia en la provisión de servicios, burocratización y desempleo.

En el caso de América Latina estas ideas se han difundido bajo las doctrinas del Consenso de Washington en consonancia con el neoliberalismo. Los programas de ajustes neoliberales recomendados hacia la región han abogado por la primacía del mercado, el recorte y la pérdida de relevancia del Estado como garante y rector dentro de la sociedad, la reducción de los programas sociales, la privatización de los sectores monopolizados estatalmente, y una disminución de su rol controlador en el manejo macroeconómico. Por consiguiente, se sugiere que el papel de este actor sea más limitado dentro de la sociedad.

En este mismo escenario aparecen las ideas a favor de otorgar mayores responsabilidades a los gobiernos locales, dado que estosactores pueden sercapaces de lograr una mayor articulación entre Estado y sociedad local, permiten encarar de una manera más adecuada las demandas locales, promueven la participación ciudadana, y por consiguiente la democratización de la sociedad a partir de acercar las decisiones a los electores; además de incentivar la conformación de redes con capacidad de articularse al mercado global, que escapan a la regulación del Estado.

Asimismo, aparece un escenario local con nuevos actores sociales que obligan a un análisis profundo respecto al rol del Municipio, donde las perspectivas de trabajo deben aparecer integradas en el ámbito local para la transformación. Esto ha significado el desmontaje de la agenda social del Estado, además de la fragmentación del movimiento social mediante la "participación ciudadana" a través de fundaciones, ONGs y otras formas de organización de la sociedad civil, donde no se produzca el acceso real de los ciudadanos al poder, aun cuando sea efectiva la acción de tales actores.

Por otra parte, los gobiernos locales, se perfilan en este escenario heterogéneo como actores sociales que pueden superar los clásicos roles operativos del gobierno municipal, tanto en sus viejas versiones burocráticas como en sus versiones gerenciales recientes. El desbordamiento de las funciones tradicionales se proyecta en dos dimensiones: hacia la ampliación de las agendas locales y hacia el desarrollo en ellas de nuevos roles estratégicos y cualitativos.

Cuba no ha estado exenta de las reformas producidas a nivel internacional, aunque no se hayan realizado desde el prisma neoliberal. Las profundas transformaciones ocurridas en el escenario de los noventa han generado la necesidad de iniciativas que contengan a los escenarios locales como actores del desarrollo.

$$
\text { La reforma tuvo impactos }
$$
importantes en las localidades; en lo económico, se aprobó la ley de inversión extranjera, la despenalización del dólar, la reestructuración del Ministerio de la Agricultura y el Ministerio del Azúcar con la creación de las UBPC, la entrega de tierras en usufructo, la autorización del trabajo por cuenta propia y la dualidad de monedas.

Desde la esfera política se han 
implementado cambios que reajustan las relaciones entre los ciudadanos y entre los distintos niveles de gobierno. Entre ellos podemos mencionar la creación de los Talleres de Transformación Integral Barrial (TTIB) por el Grupo de Desarrollo para la Capital, expandiéndose por los barrios de Ciudad de La Habana en los noventa; así como las modificaciones creadas en la Nueva Ley Electoral. Un segundo grupo, que también parece reajustar estos dos tipos de relaciones, está formado por otras medidas descentralizadoras de carácter más administrativo como, por ejemplo, la formación de los Consejos Populares (creados en 1991) y Consejos de la Administración Municipal, la reestructuración de los Ministerios y la modernización de las funciones de los gobiernos locales, y la exhortación a estos a crear sus estrategias de desarrollo local.

Todas ellas han perseguido la meta de dinamizar el ejercicio de la toma de decisiones y/o de democratizarlas (Hernández, 2005). También para 1996 se creó el Grupo Ministerial de Trabajo Comunitario Integrado por un grupo de ministerios que tenían como objetivo concertar e integrar las acciones de los organismos nacionales en relación con las comunidades y fortalecer las relaciones de apoyo y control a las administraciones locales.

Algo similar ha sucedido con los Consejos Populares. La reflexión generada alrededor de los logros y desaciertos de esta nueva estructura local también ha sido amplia. Varios estudiosos han considerado sus posibilidades como marco idóneo para canalizar la participación popular, y un escalón superior para el autogobierno local. Pero en gran medida, como enuncia García Brigos (1996), ha existido cierta tendencia a convertirlo en una instancia administrativa más, escasamente consultada para los procesos de toma de decisiones.

La viabilidad de un modelo de desarrollo nacional que incorpore más el ámbito local puede sustentarse no solo en el agotamiento de los recursos centrales del Estado para enfrentar la demanda acumulada y las crecientes necesidades sociales, sino en que las localidades pueden aportar desde sus propias potencialidades (Pérez Díaz, 2006). El nivel local parece ofrecer mejores posibilidades para la distribución equitativa de los bienes materiales y espirituales, ya que el modo centralizado que tiende a ser homogenizador y menos eficiente. El camino hacia el perfeccionamiento de la participación ciudadana en la sociedad cubana actual exige una mayor promoción de las localidades no sólo en la construcción de los destinos locales y, sino también en una concepción del desarrollo nacional.

Los estudios del desarrollo local en Cuba requieren una revisión crítica de teorías y prácticas del desarrollo local que se producen a nivel internacional, desde nuestra concepción, que parte de la premisa de la justicia social y la participación ciudadana en el proceso de construcción de la sociedad cubana. Esto constituye un asunto complejo debido a las particularidades del sistema político, económico y social históricamente constituido.

El territorio ha sido un tema que emerge entre los académicos y los sujetos decidores cubanos tanto por sus capacidades, fortalezas y debilidades como por convertirse en un factor clave para el desarrollo de la sociedad. Desde este nivel los gobiernos y las instituciones locales aparecen como actores que pueden asumir mayores responsabilidades en torno a problemáticas que comienzan a descentralizarsehaciaelnivellocal.Esvisible como estos actores están resurgiendo como parte importante de la agenda nacional y local del desarrollo, donde empiezan a dar respuestas a partir de la utilización de sus capacidades y recursos propios en función de implementar políticas integrales.

Se trata de la construcción de un modelo de desarrollo local para nuestras municipalidadesquemanejeacertadamente las tensiones entre centralización $y$ descentralización por medio de una 
planificación nacional y territorial-local en un sistema integrado que potencie todas las instancias y recursos disponibles en cada nivel. El modelo cubano transita, según los cambios ocurridos, hacia un proceso que debe estar más caracterizado por una relación más horizontal, y co-participada de la superestructura con las bases.

Es visible como algunas autoridades locales como gobiernos municipales, el Partido en determinados municipios, y otras estructuras que descansan en el nivel municipal se interesan por el tema y han generado acciones concretas en este sentido, unas han proporcionado ciertas expectativas a la ciudadanía y otras se han mostrado incapaces de sostenerse por si solas o asentarse sobre marcos instituciones establespara sucontinuidad. Muchossonlos factores que atentan en la realidad cubana actual sobre los procesos de desarrollo local, donde altas esferas políticas y económicas del país se están pronunciando como actores promotores a diferencia de décadas anteriores. Las debilidades presentadas, reproducidas y reconocidas por etapas en nuestro proceso de construcción socialista complejizan estructurar nuevas maneras de acción social con esquemas organizativos descentralizados y orientados a otorgar protagonismo local.

Sin dudas existe consenso que la continuidad del sistema político, social y económico cubano requiere buscar un modelo más eficiente y capaz de hacer frente a las demandas que se diversifican y amplían en las condiciones actuales, que dé reconocimiento protagónico a las escalas locales. La problemática del desarrollo local parece perfilarse como una alternativa para superar los problemas y las demandas escalonadas de la población, sobre todo a nivel de base.

Los Órganos Locales de gobierno en el contexto de una economía centralizada y planificada desde la garantía que representaba la inserción de Cuba en un sistema económico socialista internacional se caracterizó, entre otros aspectos, por la estabilidad de su desempeño (con un alto nivel de dependencia de las instancias superiores) y la efectividad de acciones diseñadas como parte de programas nacionales que solucionaban las necesidades básicas de la población, replicadas en los diferentes territorios en aras de la equidad, aunque casi siempre de carácter sectorial e igualitario. Todo ello lastró las prácticas autotransformativas locales.

La crisis de los noventa hace emerger con significativa importancia el papel de los gobiernos locales, no solo en administrar eficientemente los recursos y decisiones del Estado, sino en la necesidad de plantearse un redimensionamiento de estos en las posibilidades de desarrollo local (Pérez Díaz, 2009). Ante esta emergencia es necesario destacar la importancia en el estudio de las problemáticas que atañen a los gobiernos locales en Cuba. Es vital profundizar en los procesos estructurales que acontecen al interior de estos órganos, las relaciones entre sus componentes, las características de la gestión municipal, las relaciones con los niveles superiores de gobierno, el papel de los gobiernos locales como protagonistas del desarrollo en las condiciones específicas de Cuba y las relaciones de estos con los sistemas territoriales.

En el presente trabajo se abordan los antecedentes del desarrollo local que se fueron materializando en la búsqueda de un modelo económico, social y político que comienza a gestarse con el triunfo de la Revolución Cubana. Se presentan las particularidades de los gobiernos locales en nuestro contexto y cómo a diferencia de la ocurrencia de procesos reales de descentralización a nivel regional, nuestro país fue orientándose cada vez más hacia un modelo excesivamente centralizado. Contradictoriamente no fueron pocos los momentos históricos en que desde las más altas esferas gubernamentales se preconizaba la necesidad de incorporar paulatinamente a los eslabones inferiores como parte del proceso de construcción nacional. Al mismo tiempo se contextualiza 
el surgimiento del tema del desarrollo local en los noventa y las iniciativas generadas a raíz de los cambios ocurridos en el período señalado. Se ofrecen también las contradicciones y rasgos más esenciales que marcan el debate por el desarrollo local y los gobiernos locales en el contexto actual. Se valoran las posibilidades que existen, desde los territorios y en especial en los gobiernos locales, para desencadenar procesos reales de desarrollo local que cuenten cada vez con la participación de los actores locales.

\section{Etapas del desarrollo local y los gobiernos locales en Cuba}

Es destacable como desde que la Revolución Cubana asciende al poder en 1959 establece la necesidad imperiosa de impulsar políticas que permitieran equilibrar las diferencias territoriales que se habían conformado históricamente desde la etapa colonial y republicana, y ante la cual el gobierno revolucionario empieza a reaccionar de manera inmediata. La búsqueda del equilibrio y la equidad entre los territorios cubanos ha sido un permanente interés desde la política del Estado cubano en la construcción del desarrollo nacional. Es a partir de esta nueva etapa en que comienzan a percibirse esfuerzos no solo en el ordenamiento territorial sino en la dotación equilibrada de infraestructuras básicas para el desarrollo de los espacios territoriales.

Dentro de las primeras reformas que tuvieron un impacto en la estructura de los territorios estuvieron las leyes de Reforma Agraria, que expropiaban las extensas propiedades y producían una redistribución de la tierra a los niveles nacional y local. En estas medidas el Estado y los campesinos empezaban a convertirse en el actor central en los territorios en el control y uso de la tierra (Pérez Díaz, 2009).

El Instituto Nacional de Reforma Agraria (INRA) además de tener un papel activo en las Reformas Agrarias fue el principal creador de los primeros órganos oficiales locales, denominados Zonas de
Desarrollo Agrario (ZDA). Desde esta institución se impulsó el fomento de cooperativas, el desarrollo de la producción agropecuaria con sedimentación territorial con criterios deequidad territorial y políticas de industrialización producidas hacia los territorios desde lo nacional para sustituir importaciones y diversificar la producción. La nueva acumulación nacional favorece el desarrollo de los territorios más atrasados, la descentralización de actividades económicas y de servicios, la configuración de territorios con capacidad para asumir sus recursos laborales, dar servicios sociales y expandir la producción con introducción de tecnologías y prácticas avanzadas en correspondencia con la época.

En los tres primeros años de la década de los sesenta las direcciones provinciales de planificación física pusieron en marcha la planificación. Estas direcciones contribuyeron a la transformación de los territorios, porque significaron una poderosa herramienta para la nueva construcción social, sobre todo en la implementación de los nuevos valores y los contenidos de acción política e ideológica. Estas direcciones intentaron desarrollar mecanismos funcionales a escala territorial porque perseguían la coordinación y la compatibilización entre los planes y los programas sectoriales que confluían a nivel territorial.

La creación en 1960 de la Junta Central de Planificación (JUCEPLAN) significó un avance importante en el proceso de planificación territorial. Para 1961 se funda la Junta de Coordinación e Inspección (JUCEI), entre cuyos objetivos se destaca coordinar los trabajos de los organismos administrativos, políticos y sociales en los diferentes niveles, lo cual evidencia elementos descentralizadores, todavía con alto grado de centralidad. Estas tuvieron dentro de su objetivo ordenar y resolver los problemas del gobierno local y establecer una relación más estrecha, orgánica y diaria entre el pueblo y su poder (Castro, 1961). En 1966 las JUCEI serían sustituidas por los Poderes Locales, 
los cuales se caracterizaban por una propuesta descentralizadora ambiciosa. Estos poderes desaparecieron en corto tiempo, influidos por la división política administrativa, la falta de recursos para encarar las demandas de la población, y la débil institucionalización de la sociedad cubana (Méndez Delgado, 2007).

La dinámica del entorno territorial cubano fue cambiando en la misma medida en que el Estado presentaba un proyecto político de justicia social, soberanía social y un modelo productivo orientado al tránsito del modelo agroexportador y monoproductor a uno agroindustrial diversificado. Las medidas revolucionarias de nacionalización de la propiedad extranjera significaron la necesidad de un reajuste a nivel territorial de las relaciones de producción, donde el Estado comenzó a asumir una actuación directa entre las necesidades territoriales y la población. En estaetapasetratadeun períododebúsqueda, de ordenamiento correspondiente al nuevo Estado que pretende desarrollar el país con herramientas de planificación central de manera diversificada, por medio de polos vinculados a una diversificación técnico-productivo que comprende transformaciones en el sector agropecuario y agroindustrial, en la industria y servicios de base urbana y rural con un creciente proceso de descentralización de servicios básicos hacia los territorios.

La década de los setenta fue un período importante en las localidades en cuanto al fortalecimiento de los organismos, las organizaciones de masas y la administración del Estado, lo que contribuyó extraordinariamente a que la sociedad cubana, en los años posteriores, se sumergiera en el proceso de institucionalización que favoreció al desenvolvimiento de la planificación territorial. En los años 1974 y 1975 se produce la experimentación de los Órganos del Poder Popular (OPP) en la provincia de Matanzas, lo que representó un paso importante en la institucionalización y en la descentralización política-administrativa del país.
La instauración en 1976 de los órganos locales del Poder Popular y de un subsistema municipal fue una acción importante en el proyecto de modernización del sistema político y estatal, el cual se denominó proceso de institucionalización. Esta institucionalización acrecentó las facultades, atribuciones y propició mayor autoridad a los municipios, los cuales asumieron la administración de un grupo de empresas y establecimientos que anteriormente eran administrados por el poder central. De este modo se facilitó el marco legal a los municipios para desarrollar con mayor flexibilidad la planificación y administración de actividades económicas y sociales (Becerra Lois \& Pino Alonso, 2005).

En el Primer Congreso del Partido Comunista de Cuba (PCC), apoyándose en estudios de factibilidad demográfica, económica y social se arriba a las conclusiones siguientes: primero es aconsejable simplificar nuestra estructura de dirección política-administrativa, mediante la supresión del eslabón regional; segundo, crear un número mayor de provincias, y tercero, reducir el número de municipios, ajustándose a un criterio de uniformidad en cuanto a área, población, actividades productivas, servicios, comunicaciones y otros aspectos. ${ }^{1}$

Esta división permitió aumentar las facultades y funciones de las provincias al conformarse los Órganos del Poder Popular, las cuales jugarían un rol importante en el ámbito económico. Los municipios se encaminaban a administrar la unidades (ahora de subordinación local) atendidas hasta entonces por los Organismos Centrales del Estado, además de facilitarles la planificación y administración de la actividad económica y social, acorde con el Sistema de Dirección de la Economía que requería "una relación adecuada entre la centralización y descentralización de las decisiones, un alto nivel de participación

1 Informe al Primer Congreso del Partido Comunista de Cuba, Editorial Pueblo y Educación. Ciudad de La Habana, 1978, p. 161. 
de las masas [...] y un alto grado de eficiencia y organización en cuanto a la gestión económica” (Rassi, 1981). Los nuevos centros municipales comenzaron a fortalecerse con inversiones administrativas y de infraestructura social.

Se abrió el camino de la institucionalización de la participación de las masas en los asuntos del gobierno de forma institucionalizada y en la solución de los múltiples problemas que afectan a la localidad. Se abogó por la creación de dispositivos de participación de la comunidad en la planificación, y en el control de sus recursos; se buscaron mecanismos para los procesos de nominación de candidatos y de elección de los delegados a las Asambleas y de los miembros de los Comités Ejecutivos del Poder Popular, la determinación de las estructuras administrativas más adecuadas, la delimitación de las funciones y relaciones entre Partido, Poder Popular, UJC, y las organizaciones de masas.Esto representó el comienzo de un camino en el marco de un complejo proyecto de modernización, descentralización y democratización del sistema político y estatal. El sistema político cubano se dotó de nuevos mecanismos de participación y legitimación que tendrían en los municipios uno de sus pivotes más relevantes (Dilla, 1993).

En 1978 se aprueba conjuntamente por el Partido y el Comité Ejecutivo del Consejo de Ministros una estrategia de desarrollo a largo plazo que tuvo como prioridad fortalecer el papel de la planificación territorial en la economía, en la cual se recoge una visión integral del desarrollo territorial basado en la política orgánica de desarrollo económico y social. (Méndez Delgado, 2007).

A pesar de crearse todo un sistema nacional organizativo y ciertas condiciones para el desarrollo de la planificación territorial los resultados esperados quedaron por debajo de lo que se pronosticaba. No se pudieron alcanzar todas las metas, pues estuvo restringido el trabajo a la organización, planificación y control de las tareas orientadas por los OPP en sus diferentes niveles.

En 1982 se realizaron discusiones en los territorios para valorar las situaciones socioeconómicas de estos, y buscar un uso más racional de los recursos en función de las prioridades nacionales y locales; garantizar niveles esperados de producción, el comportamiento probable de las exportaciones, el desarrollo de las inversiones, la eficiencia controlada desde los territorios y el manejo acertado de los recursos locales.

En 1983 se creó una comisión con el objetivo de perfeccionar la DPA de 1975. En esta comisión afloró que se había producido un desarrollo socioeconómico ascendente enlaescala provincialdondeseincorporaban los territorios más atrasados del país. En contraste un grupo de municipios, sobre todo del oriente, seguía careciendo del suficiente potencial económico y social para desde las administraciones locales resolver aceptablemente con cierta autonomía las problemáticas locales (Méndez Delgado, 2007). Se demandaba un nuevo órgano que pudiera fiscalizar la calidad y eficiencia en la prestación de servicios de los organismos y entidades en su demarcación, e impulsar la solución de los problemas eminentemente propios de la localidad. La experiencia había demostrado que cuando un lugar perdía su condición política-administrativa, se observaba posteriormente el debilitamiento de su desarrollo económico y social. La delimitación de los territorios como resultado de conformar unidades económicas en sí mismas, en muchos casos había traído como consecuencia la ruptura de redes de identidad (Pérez Díaz, 2009).

Lo anterior se ratificó en la Resolución sobre el perfeccionamiento de la DPA del Tercer Congreso del PCC. En este momento se aprueban las bases para la creación de los Consejos Populares, realizándose las primeras experiencias puntuales en las zonas rurales del país (Guzón, 2001).

En el período de 1986-1990 las Asambleas del Poder Popular fueron escenario de discusión de los planes 
económicos en sus diferentes niveles; en este espacio se discutían tanto las problemáticas municipales que podían ser resueltas a estos niveles como en otros.

Desde inicios de los ochenta ya empezaba a emerger una serie de limitaciones, algunas desde años anteriores, las cuales impedían una articulación eficaz de todos los componentes que debían intervenir en el plan económico territorial. La falta de cooperación entre los organismos enclavados en un mismo territorio sobresale hasta la actualidad como factor clave en el desarrollo territorial integrado, porque impedía el uso eficiente de las potencialidades en las localidades.

Otras dificultades percibidas desde mediados de los 8o fueron los insuficientes métodos para la confección, control y ejecución de los proyectos que no garantizaban la participación de los diferentes organismos que debían implicarse en los planes. La falta de coordinación entre los organismos hizo mella no solo en la elaboración sino también en la puesta en práctica de los planes territoriales, donde los OPP fueron incapaces de lograr una horizontalidad con las instituciones y organizaciones de niveles superiores de subordinación, sobre todo por el marcado sectorialismo que se empieza a evidenciar desde entidades nacionales.

El Tercer Congreso del PCC intentó superar e impulsar a una fase superior la planificación territorial, en busca de un perfeccionamiento del SDPE. Se enfatizó en el papel activo que debía desempañar los órganos locales en sus territorios, y cómo estos debían involucrar y coordinar los procesos de planificación territorial con el objetivo de que se involucraran más en los procesos de dirección de la economía nacional. Como aditivo se señaló que las provincias tenían posibilidades decisorias, pero siempre en concordancia con los planes previstos.

Hasta finales de los ochenta puede decirse que se trabajó incesantemente en el establecimiento de las bases organizativas y las condiciones necesarias para garantizar un desarrollo más equilibrado de los territorios y reducir las disparidades. Se intentó que la planificación territorial pasara a una etapa superior para garantizar la proporción debida en el desarrollo económico y social de los territorios, lo que permitiría una participación más activa de los órganos locales del Poder Popular, y que los objetivos previstos en los planes correspondieran con las decisiones que tomaran las provincias (Becerra Lois \& Pino Alonso, 2005).

Aun cuando existieron estos intentos de descentralización en todo el período recorrido, puede afirmarse que hasta finales de la década de los ochenta, el sistema de planeamiento físico y económico a partir de los gobiernos locales creados en 1975, se estructuró de manera marcadamente centralizada, lo cual no facilitaba la participación de la sociedad local, ni de sus instituciones de base, de gobierno o administrativas, ni de la propia comunidad en su concepción y ejecución. Por otra parte, la primacía del planeamiento sectorial sobre el territorial, generaba frecuentes problemas de falta de integralidad del proceso inversionista en los niveles locales. (García Pleyán, 1998).

La estrategia general se orientó, entre otros aspectos, a considerar la integridad entre los aspectos económicos y sociales del desarrollo y a extender las políticas sociales a todo el territorio nacional, donde los municipios en la nueva división y con las nuevas atribuciones desempeñaron un papel significativo en la implementación de tales objetivos centrales. El énfasis estuvo en las provincias, ciudades intermedias o secundarias y en las zonas rurales, lo que favorecía la integración entre el campo y la ciudad.

\section{La reivindicación de los gobiernos locales y el desarrollo local como alternativa a la crisis en Cuba}

A pesar de los logros alcanzados en 
la descentralización del sistema productivo y de servicios (educación, cultura, salud y comunales) hacia los municipios, desde la década de los ochenta el sistema político cubano se caracterizaba por un alto grado de centralidad, en contraste con las reformas que se daban en América Latina. El Estado cubano ejercía una elevada verticalidad sobre las instituciones políticas, económicas, socialesygubernamentales. Desdeestaforma de organización que se había conformado tras décadas de gestación, el Estado generó índices importantes de bienestar, desarrollo humano, industrialización, maduración de instituciones que se habían creado tras la efervescencia revolucionaria; además del compromiso con su pueblo (Hernández, 2005).

Lagobernabilidadempezabaamostrar ciertos síntomas de agotamiento como causa de la crisis del modelo de desarrollo económico (Hernández, 2005), de una crisis estructural solapada y una ausencia de inserción en el mercado internacional capitalista. El ritmo de crecimiento había decrecido considerablemente para el último quinquenio de la década de los ochenta, a diferencia de 1981 a 1985 en que la regularidad del crecimiento del PIB era de un $7 \%$, ya para el último quinquenio era de solo el $0,7 \%$.

La crisis estructural que vivía el país se hizo más profundo y evidente para 1989, cuando empieza a desarticularse el campo socialista, lo que resultó un suceso que afectó la estabilidad del modelo cubano y detener procesos de transformación que venían produciéndose desde décadas anteriores. La pérdida de las relaciones comerciales con el bloque eurosoviético detuvo el proceso de rectificación y el país tuvo que emprender una reconstrucción de las relaciones de producción para insertarse en la lógica del mercado.

Un cúmulo de iniciativas se generalizó por todo el país para intentar revertir la desfavorable situación. Algunas de ellas aparecieron con el apoyo del Estado, otras con el financiamiento de las ONGs extranjeras que empezaron a otorgar recursos para concretar diversos proyectos locales de desarrollo. En el caso de las que contaron con apoyo estatal se encontraron las experiencias que sucedieron en algunas localidades del país donde los Consejos Populares consiguieron llenar espacios de coordinación y gestión a partir de nuevas agendas, y que el Estado no podía satisfacer con eficacia (Caño, 1998). Los Consejos Populares fueron promotores, también, de lo que se ha denominado movimientos comunitarios en Cuba (Dilla, Fernández, \& Castro, 1996). Estos empezaron a desempeñar un papel protagónico en la movilización de los recursos locales, en el mejor aprovechamiento de los recursos centrales, en el incentivo a la innovación social, en identificar efectivamente las prioridades de la base y en la mejoría de la calidad de vida de los ciudadanos.

Un grupo de experiencias en desarrollo comunitario se generalizaron, en esta etapa, y pueden considerarse antecedentesal debateyacciones en materia de desarrollo local que emerge a finales de los noventa. Estas experiencias resultaron novedosas en la manera en que enfocaron algunos aspectos como la utilización de recursos locales para generar iniciativas, el papel otorgado a los actores de base en los procesos de participación, planificación, cooperación e integración para el cambio, la atención a los problemas de la economía local y la transformación integral del espacio local. Para la generalización de estas iniciativas surgidas al calor de la crisis se crearon comisiones de trabajo comunitario desde la Asamblea Nacional, las cuales intentaron extender el papel de la comunidad como agente transformador.

Sin dudas las reformas económicas se hacían incompatibles con algunos aspectos con los que tradicionalmente había funcionado el sistema de gobierno cubano. Este sistema caracterizado por el excesivo centralismo en la planificación, el alto grado de verticalidad y el burocratismo en plena expansión entorpecía los nuevos mecanismos de regulación y articulación económica que se creaban para salir de 
la crisis. La creación de nuevos actores económicos y transformación de otros significó que los espacios de actuación de estos se vieran transformados hacia una dinámica de interrelaciones diferentes. Las municipalidades cubanas y en especial los gobiernos locales debían comenzar a interactuar con estos actores, para lo cual debían recibir un marco legal que les propiciara tal relación.

En 1992 fue necesaria una Reforma Constitucional que reestructurara las formas de propiedad y algunos rasgos del propio sistema de gobierno cubano ya que se necesitaba un marco legal para responder a los desafíos que la realidad imponía. Con las modificaciones la propiedad estatal empezaba a coexistir con otras formas de propiedad, en las cuales se redefinía el régimen de propiedad socialista (Hernández, 2005)

En el plano gubernativo se produjeron cambios significativos con vistas a transformar la estructura y funcionamiento del Poder Popular, en 1992 la Asamblea Nacional del Poder Popularaprueba la Leyde Reforma Constitucional mediante la cual se introducen cambios en estos órganos tales como (Constitución de 1992) sustitución de los Comités Ejecutivos de las Asambleas Provinciales y Municipales por los Consejos de Administración, Establecimiento del voto libre, directo y secreto para la elección de diputados al parlamento y miembros de las Asambleas Provinciales al igual que en el caso de las Asambleas Municipales, se realizaron precisiones sobre la gestión gubernamental en provincias y municipios con vistas a conceder más autoridad a delegados y asambleas y se instituyó constitucionalmente el Consejo Popular.

La división política-administrativa aplicada en los setenta demostró que la participación de la población seguía siendo aún distante y se perdían las funciones de fiscalización y control de la actividad de gobierno por parte de la población. La estructura municipal así concebida alejaba una parte considerable de la población de las estructuras administrativas y las diferentes entidades a cargo de la satisfacción de las necesidades del pueblo, con una tendencia a ubicarse en las cabeceras municipales (Dilla, 1996).

Partiendo de tales insuficiencias, la nueva estructura política-administrativa demostró que era necesario crear un eslabón intermedio entre el municipio y la población. Es entonces que surge la iniciativa de creación de los Consejos Populares, experiencias que comienzan por las zonas rurales, suburbanas y en 93 urbanas de Ciudad de La Habana, siendo en 1991, mediante la aprobación del Acuerdo III - 138, de la Asamblea Nacional del Poder Popular que se extiende esta experiencia a todo el país. La formación de los Consejos Populares buscó establecer, además, facilidades organizativas, administrativas y de servicios para los habitantes de aquellos asentamientos que dejaron de ser cabeceras municipales históricas. Fueron diseñados para construir una autoridad subordinada al municipio que por su naturaleza fuera una forma de autogobierno en la base. Estos constituyen un "órgano del Poder Popular, local, de carácter representativo [...] apoya a la Asamblea Municipal del Poder Popular en el ejercicio de sus atribuciones y facilita el mejor conocimiento y atención de las necesidades e intereses de los pobladores en su área de acción"2.

El Estado cubano quería dar otro impulso y seguir perfeccionando el aparato del poder popular, sobre todo en las condiciones excepcionales que vivía el país en las cuales se necesitaba aumentar el protagonismo de la población y de los niveles inferiores. Era necesario empoderar a los gobiernos municipales para controlar, fiscalizar e interrelacionarse con los nuevos agentes económicos estatales y no estatales presentes en sus comunidades, por lo que se demandaba que estos tuvieran una implicación más directa en los asuntos de la economía local. En sentido los Consejos

2 Ley No. 91 de los Consejos Populares. Gaceta Oficial de la República de Cuba, Edición Extraordinaria No. 6, julio, 2000. 
Populares deberían desempeñar un rol esencial como un embrión de autogobierno local.

La Reforma Constitucional avanzó en el tema de los gobiernos locales en el sentido en que se reafirma el carácter legal de estos y se redefinen ganando en claridad y concreción en sus funciones y las de sus estructuras (Hernández, 2005). Los gobiernos locales (Asambleas Municipales del Poder Popular) quedarían definidos como "los órganos superiores locales del Poder del Estado y en consecuencia, estarían investidos de la más alta autoridad para el ejercicio de las funciones estatales en sus demarcaciones respectivas y para ello, dentro del marco de su competencia y ajustándose a la ley, ejercen gobierno"3. Se buscaba que estas instancias pudieran desde una perspectiva integral fiscalizar la calidad y eficiencia en la prestación de servicios e impulsar la solución de un grupo de problemáticas desde la localidad.

La planificación centralizada adquirió un carácter más financiero y descentralizado. En relación con las nuevas reformas, el aseguramiento material pasó a ser de una actividad de Estado a una esfera comercial y económica (González Gutiérrez, 2001). Se produjo un cambio en la planificación, se pasó de la elaboración de balances materiales a una planificación financiera y con un carácter más inmediato y descentralizado (Campos Carrera, 2005).

En la Reforma Constitucional de 1992 las responsabilidades de los gobiernos locales se vieron ampliadas por el papel que se les otorgó en el diseño, ejecución y control del presupuesto municipal. Estos por primera vez tenían que elaborar el presupuesto municipal en coordinación con las estructuras de los órganos globales de la economía. Las Asambleas Municipales del Poder Popular confeccionan el anteproyecto de presupuesto que debe ser presentado en la sesión de la Asamblea Municipal para posteriormente enviarse al

3 Capítulo XII, Art. 103. Ley de Reforma Constitucional. La Habana, 1992. nivel provincial. Una vez aprobado el plan y comenzada la ejecución del presupuesto debe ser sometido a una periódica rendición de cuentas (Campos Carrera, 2005), lo cual demuestra una vocación participativa.

En los noventa, como consecuencia del escenario antes mencionado, se empezaron a introducir las posibilidades de desarrollo local en Cuba, en consonancia con el desarrollo nacional y articulado desde todos los niveles de distribución geográfica y política expresados en la realidad cubana. Un grupo considerable de autores y actores formuló la necesidad de que las construcciones en materia de desarrollo local se articulen en los tres niveles: nacional (macro), meso (provincial) y local (municipal) y donde los gobiernos locales sean más activos.

También la noción del desarrollo fue enriquecida con otros aspectos que vienen a perfeccionar el concepto, en este caso el desarrollo local. Se ha enunciado la necesidad de una construcción que sea centrada en el factor humano -en los aspectos de su calidad de vida, en el reconocimiento de sus responsabilidades, derechos sociales y valores espirituales-, la cual supone la adopción de estrategias políticas orientadas a tal fin (PNUD, 1996). Esto presupone seguir perfeccionando varios indicadores relacionados con el desarrollo humano en que el país ha venido trabajando a lo largo del período revolucionario.

Nuestros académicos han considerado importante el papel que pueden desempeñar las pequeñas $\mathrm{y}$ medianas empresas (PYMES), el sector por cuenta propia y la empresa estatal perfeccionada como actores potenciadores de la estructura económica local cubana, la necesidad de atender el enfoque transversal de género, la participación de los ciudadanos, la descentralización como requisito indispensable; el papel de la economía local; el fortalecimiento de la institucionalidad; el enfoque medio ambiental; la función de la historia, valores, tradiciones y cultura enraizadas 
en el territorio; las potencialidades locales, la cooperación e integración económica y social, y la capacidad de movilización de las fuerzas productivas locales. Junto con el interés intelectual por el tema del desarrollo local se han desarrollado en el país un conjunto de experiencias que han permitido la movilización de las potencialidades internas de los territorios y de los conocimientos que van adquiriendo los actores locales de base.

El tema del desarrollo local ha centrado su atención en nuestro escenario con peso en los gobiernos locales como actores claves (González Mastrapa, 2005; Guzón, 2001). Esta coincidencia sugiere que los procesos de desarrollo local incorporen a los gobiernos locales como actores activos en los procesos impulsores, facilitadores y catalizadores de las iniciativas que se implementen. En estos procesos la planeación estratégica puede resultar un instrumento de construcción importante para la concreción de los intereses del desarrollo local.

Los gobiernos municipales, pueden formular su estrategia de desarrollo local, basándose en la combinación efectiva de los factores de producción a escala del territorio y lograr utilizar de forma eficaz los recursos provenientes de planes y programas exógenos que se insertan en el mismo, mediante un conjunto de acciones de futuro que permita un despliegue ínter institucional e intra institucional orientado al mejoramiento del bienestar de todos los miembros del territorio a corto, mediano y largo plazos, en cuanto a sus valores, su cultura integral, su medio ambiente natural, la educación, la salud, la producción, el consumo y su seguridad íntegra. El desarrollo local debe elaborarse desde el nivel municipal porque es donde se pueden concertar políticas locales, y porque los gobiernos locales poseen ciertos niveles de atribuciones. Es en este nivel local donde se pueden articular los diferentes niveles de subordinación: empresarial, institucional y gubernamental.

El desarrollo local, en las condiciones concretas cubanas, implica cierta capacidad de los actores de la localidad para el diseño, implementación, evaluación y sistematización de políticas y servicios sociales, de programas y proyectos de transformación con enfoque comunitario, integrados y articulados con los intereses nacionales y que ofrezcan respuesta a las contradicciones identificadas a partir del liderazgo de los Consejos Populares y las Asambleas Municipales del Poder Popular en la planificación del desarrollo económico y social territorial, donde la participación y cooperación de los sujetos locales posibilitan la elección consciente de proyectos dirigidos a la solución progresiva de las contradicciones.

Los gobiernos locales requieren convertirse en sujetos proactivos de su entornopara transformarlas estructurasque pueden facilitar los procesos de desarrollo local. En un complejo y heterogéneo contexto (internacional, nacional y local) deben mejorar su capacidad de gestión del bienestar de las comunidades existentes en demarcación, en relación con las potencialidades y limitaciones con que conviven. Deben estimular iniciativas que permitan un aprovechamiento eficiente de los recursos asentados en el territorio. (Pérez Díaz, 2006).

Los gobiernos municipales cubanos pueden estimular elementos esenciales del desarrollo local como la cooperación, integración, creación de redes, eslabonamientos y conformación de tejidos, lo que permitirá sobreponerse a las barreras sectoriales que obstaculizan la eficiente co-gestión de las necesidades locales.

Desde las agendas locales estos actores pueden rescatar el papel de las economías locales y articularlas en el territorio, establecer políticas de desarrollo integrales a nivel local donde las municipalidades desempeñen un rol protagónico en estrecha participación con los actores que son portadores del desarrollo local. Los gobiernos municipales pueden estimular generación de riquezas 
por medio de actividades a pequeña escala que permita satisfacer el mercado local y desencadenar procesos de comercialización de productos en otros territorios.

A nuestro juicio, para que se produzcan verdaderos procesos de desarrollo local que permitan hablar de un modelo de desarrollo nacional coherente con esta nueva estrategia lanzada por el país, es imprescindible que el Estado Cubano estimule las siguientes transformaciones: 1) la promoción de una voluntad política para favorecer procesos de descentralización que rebasen la meramente estructural o administrativa de los órganos de gobierno tanto intermedios como inferiores, que estos sean dotados de facultades, recursos, decisiones, problemáticas, motivaciones para captar ingresos, y posibilidades para generar y financiar sus propios proyectos y posibilidades de gestar alianzas entre los diferentes actores locales o supralocales, y que los gobiernos locales puedan participar activamente en la economía local; 2) desarrollar cambios estructurales sustentados en marcos jurídicos que amparen el ejercicio de la gobernabilidad local en leyes específicas que otorguen autoridad, jerarquía, posibilidades de fiscalización, horizontalidad y concertación con los diferentes sujetos económicos e institucionales que radican a nivel local; 3) no universalizar u homogeneizar las iniciativas que se han ido suscitando bajo los mismos patrones ya que cada situación exige respuestas únicas e irrepetibles; 4) que se capte y comprenda la esencia del desarrollo local, lo cual no significa, únicamente, enfocarse en enfrentar problemas y en perderse en la trama diaria de la cotidianidad. Significa reconocer el territorio como una totalidad diversa que encierra conflictividad y potencialidad, donde se presenten propuestas que rebasen el sentido de contingencia y urgencia como método tradicional utilizado por las autoridades locales; 5) seguir ampliando el espectro de actores económicos, en lo fundamental sectores no estatales que pueden contener formas socialistas de economía y algunos de economía privada en las diversas áreas que hoy existen, y nuevas iniciativas de pequeñas y medianas empresas en las que se pueden ampliar en el tejido socio-productivo local y que puedan estar sedimentadas en el territorio e interactuar con los gobiernos locales en relaciones no antagónicas y más colaborativas. Los gobiernos locales pueden estimular emprendimientos, crear entornos favorables y propicios a la cooperación y alianzas estratégicas; 6 ) que los gobiernos locales (de manera cooperada y participativa) puedan y contengan agendas particulares de desarrollo basadas en recursos asignados centralmente y recursos que sean capaces de captar y ampliar para su reinversión; 7) transitar a un modelo de desarrollo que conjugue la participación ciudadana e institucional y donde los individuos no se diluyan en la delegación hacia sus representantes; 9) atender la ineficacia y el desgaste ocasionado por la pérdida de vitalidad de la institucionalidad cubana enquistado en los ambientes locales y que ha repercutido en la pérdida de legitimidad de instituciones e incluso de los gobiernos locales ante la ciudadanía, lo que se traduce en escasas fórmulas y proyectos que desde estos niveles satisfagan niveles elementales de calidad de vida local.

\section{A manera de conclusión}

La búsqueda de un proyecto de economía nacional se ha caracterizado por diferentes variantes y métodos de ejecución. A partir de 1960 se empieza a estructurar un sistema que sentó las bases para un desarrollo armónico y proporcional en la distribución de las riquezas. Este proceso, aunque estuvo marcado por un enfoque "del centro al territorio", pretendió aprovechar las ventajas de los recursos naturales, humanos, de infraestructura y capacidades instaladas en los territorios para las inversiones con vistas al desarrollo.

Desde las primeras etapas de la planificación territorial hasta la actualidad el Estado ha carecido de un 
enfoque sistémico para el desarrollo de las localidades por prevalecer, en los objetivos de ordenamiento y construcción territorial, una planificación sectorial y altamente centralizada. Esta práctica ha desconocido al territorio, sobre todo hasta los noventa, como un factor activo en el desarrollo en su alto contenido como potencialidad. El modelo económico y social cubano hasta 1990 avanzó progresivamente hacia la construcción de un modelo de transformación estructural que reforzaba el poder del Estado como líder del desarrollo económico y social.

Por su parte, los gobiernos locales creados a mediados de los setenta no representaron los actores co-protagónicos esperadosparaeldesarrollodelosterritorios. Los gobiernos locales permitieron asegurar la transmisión de políticas, programas, infraestructura y recursos desde el nivel central hacia los municipios permitiendo procesos de acumulación de capital para la redistribución nacional, garantizar la igualdad y mejorar los indicadores sociales desde una perspectiva humana del desarrollo. El modelo de gobernabilidad centralizada no ha logrado que los gobiernos locales se acerquen al liderazgo protagonizado por el Estado, primando un modelo de relación Estado-ciudadanía más que un esquema gobierno local-ciudadanía. Por varias razones (sectorialismo, verticalismo y descentralización real) no se ha podido lograr una horizontalidad de los actores locales para una planificación integral, lo que generado deficiente utilización de los recursos locales.

Todo parece indicar que los gobiernos locales están destinados a convertirse como agentes centrales en estos procesos que se empiezan a vislumbrar desde la década de los noventa y en fechas tan recientes. El papel de los gobiernos locales puede consistir en una prestación y administración eficiente de servicios, una mayor participación de la comunidad en los asuntos locales y la generación dedinámicas tendientesa favorecer prácticas (productivas, culturales y sociales) que los conviertan en gestores del desarrollo.
El proceso de modernización que se exige para los gobiernos locales cubanos requiere de un Estado que aumente su capacidad de planificación estratégica y de gestión en los diferentes niveles territoriales y sectoriales y propicie mecanismos de cooperación entre los actores locales. Para lograr este propósito se deben asegurar ciertos requerimientos básicos como el contar con una planificación participativa que dé prioridad a las instancias locales; el desarrollo de modelos innovadores para la gestión, producción y servicios; y la puesta en marcha de un proceso de capacitación permanente a las administraciones locales ajustado a sus demandas.

\section{Referencias Bibliográficas}

Becerra Lois, F., \& Pino Alonso, J. R. (2005). Evolución del Concepto de Desarrollo e Implicaciones en el Ambito Territorial: Experiencia desde Cuba. Economía, Sociedad y Territorio, 5(17), 85-119.

Campos Carrera, J. C. (2005). Descentralización y desarrollo local en Cuba. La Habana: Grupo de Estudios Laborales, Centro de Investigaciones Psicológicas y Sociológicas (CIPS).

Caño, M. C. (1998). Cuba: el desarrollo local en los 9os. En Roberto Dávalos (Ed.), Desarrollo Local y Descentralización en el contexto urbano. La Habana: Universidad de La Habana, Departamento de Sociología.

Castro, R. (1961). Discurso en acto de creación de la JUCEI. La Habana.

Dilla, H. (1993). Cuba: la crisis y la rearticulación del consenso político. Notas para un debate socialista. Cuadernos de Nuestra América, 5(20).

Dilla, H. (1996). Municipios y construcción democrática en Cuba. Perfiles Latinoamericanos, (8).

Dilla, H., Fernández, A., \& Castro, M. (1996). Movimientos barriales en Cuba: un estudio comparativo. En A. Vázquez, \& R. Dávalos (Eds.), Participación social. Desarrollo urbano y comunitario. La Habana: Universidad de La Habana, 
Departamento de Sociología.

García Brigos, J. (1996). Gobernabilidad y democracia: los órganos del poder popular en Cuba, Informe de Investigación. La Habana: Instituto de Filosofía.

García Pleyán, C. (1998). ¿Quién planifica el territorio? Un balance crítico de la cuestión en los 9o. En R. Dávalos (Ed.), Desarrollo Local y descentralización en el contexto urbano. La Habana: Universidad de La Habana, Departamento de Sociología.

González Gutiérrez, A. (2001). Vigencia de la planificación. Cuba Investigación Económica, 7(4).

González Mastrapa, E. (2005). El proceso histórico de los territorios en Cuba. En Taller Universitario sobre Desarrollo Local. Universidad Central "Marta Abreu" de Las Villas.

Guzón, A. (2001). Potencialidades de los municipios cubanos para el desarrollo local [Tesis de maestría]. Centro de Investigaciones Sociológicas y Sicológicas, La Habana.

Hernández, A. (2005). Cuba en los 9o: la descentralización como alternativa a la crisis económica [Tesis de doctoral]. Universidad de La Habana, Departamento de Sociología.
Méndez Delgado, E. (2007). Análisis territorial del desarrollo humano en Cuba, 1985-2004. Revista de Comercio Exterior, 57(8).

Pérez Díaz, A. (2006). Condiciones para el desarrollo local en Cuba. Estudio de caso en el municipio Manicaragua. En Memoria CD II Encuentro teórico universalización y sociedad. Santa Clara: Editorial Feijóo, Universidad Central "Marta Abreu" de Las Villas.

Pérez Díaz, A. (2009). Antecedentes históricos del desarrollo local en Cuba. En Memoria CD IX Taller Internacional Comunidades: Historia y Desarrollo. La responsabilidad individual $\mathrm{y}$ organizacional desde el enfoque comunitario. Santa Clara Editorial Feijóo, Universidad Central "Marta Abreu" de Las Villas.

PNUD. (1996). Desarrollo humano. Informe 1996. Madrid: Mundi Prensa.

Rassi, R. (1981). Cuba: Nueva División Político-Administrativa. La Habana: Editorial ORBE.

\section{Sobre el Autor}

Addiel Pérez Díaz

Licenciado y Maestro en Sociología por la Universidad de la Habana y Doctor en Ciencias Sociológicas por la Universidad Centra "Marta Abreu" de las Villas (Cuba). Ha sido vicedecano de investigación y postgrado de la facultad de Ciencias Sociales en la Universidad Central "Marta Abreu" de las Villas; coordinador e investigador de varios proyectos en temáticas como el desarrollo local, gobiernos locales, desarrollo comunitario y estudios de población. Profesor invitado y becario en diversas universidades españolas. Profesor de la Licenciatura en Sociología, maestría y doctorado en Desarrollo Comunitario en la Universidad Central de las Villas, donde trabajó de 2001 al 2013. Profesor de la Maestría en Sociología de la Universidad de la Habana. De 2013 a la actualidad es Profesor de Tiempo Completo, adscrito al departamento de Ciencias Sociales en la Universidad Autónoma de Ciudad Juárez. Es miembro del Sistema Nacional de Investigadores. Ha escrito ocho artículos en revistas indexadas, y más de una veintena, entre libros y capítulos sobre las temáticas anteriormente enunciadas. 